\title{
Minorias Étnico-Religiosas Implantadas en España: Desigual Función y Posición de Dos Iglesias de Habla Inglesa en Málaga ${ }^{1}$
}

\author{
María Ángeles Escriva Chorda \\ Universidad de Huelva, España \\ Jacqueline Castro \\ Pontificia Universidad Católica del Perú
}

\section{Resumen}

Este artículo contribuye a sopesar los efectos del actual pluralismo religioso en España que se descubre por el aumento y diversificación de población con experiencia de vida en el exterior. Primero, esta discusión se plantea en el marco del monopolio de la Iglesia Católica que ha dominado durante siglos, a fin de contrastar la realidad española contemporánea, que se podría definir de sociedad de pluralismo religioso reciente y moderado, con las realidades de otros países en Europa y Norteamérica. En segundo lugar, como estudios de caso, se presentan dos congregaciones cristianas de habla inglesa en la ciudad de Málaga (Andalucía) y se señalan los factores endógenos y exógenos al grupo que determinan que cada una cumpla diferentes funciones y ocupe diferente posición en la sociedad receptora. Entre estos factores destacan el diferente papel de la afiliación religiosa como marcador étnico, así como la influencia de características socioeconómicas, fisonómicas y culturales. Estos dos casos y la discusión inicial ayudan a aventurar el futuro de las confesiones

1 Este artículo se basa en información recopilada a través de una investigación titulada "Religión e Inmigración" y que fue financiada durante 2005 por la Fundación Centro de Estudios Andaluces y durante 2006 por la Dirección General de Coordinación de Políticas Migratorias de la Junta de Andalucía. 
minoritarias, así como el impacto que éstas alcancen en el devenir de lo religioso en una cada vez más secularizada España.

\begin{abstract}
This article contributes to weigh up the effects of current religious pluralism in Spain that it results from an increase and diversification of population with life experience abroad. Firstly, this discussion anchors in the framework of Catholic Church monopoly that has dominated along centuries, in order to contrast contemporary Spanish reality, that could be defined as a society of recent and moderated religious pluralism, with the realities of other European and North American countries. Secondly, two English speaking Christian congregations located in the city of Malaga (Andalusia) are introduced as case studies, and the endogenous and exogenous factors that determine their different functions and positions in the receiving society are remarked. Among these factors the text emphasizes the different role of religious affiliation as an ethnic marker, and the influence of socioeconomic, physiognomic and cultural traits. The two cases and the initial discussion help to venture the future of minority confessions and their impact in an increasing secularized Spain.
\end{abstract}

\title{
INTRODUCCIÓN
}

Desde hace un par de décadas, España se ha convertido en un país atractivo, tanto para los europeos del Norte que desean pasar el último tercio de sus vidas en tierras más cálidas, como para muchos migrantes procedentes de África, América Latina, Europa del Este o Asia, en búsqueda de una mejora social y económica. Además del Islam $\mathrm{y}$ otras creencias, un buen número de estos nuevos ciudadanos profesa el cristianismo en sus diferentes corrientes, por lo que, o bien se incorporan a las iglesias locales o, con frecuencia, forman sus propias iglesias. De este modo, la nueva inmigración, tanto la privilegiada del Norte como la desfavorecida del Sur, aporta mayor diversidad al panorama religioso de un país, hasta hace bien poco bajo el monopolio absoluto de la Iglesia Católica. 


\section{Contexto histórico}

En pequeñas y grandes ciudades de España se observa la huella de la reciente inmigración en el crecimiento e implantación de cultos y manifestaciones religiosas diversas (Estruch et al., 2004; Piedrahita, 2005). Esta presencia transforma el paisaje local y desafía las costumbres y el orden social existente entre los nativos. De entre todas las reacciones, destaca la consternación que provoca entre muchos españoles la reimplantación del Islam, debido a un imaginario colectivo anclado en una larga historia de conflictos y desencuentros entre la ribera Norte y Sur, el Oeste y el Este del Mediterráneo (Said, 1979; De Arístegui, 2005). Una historia que también recuerda que, tras la recristianización de AlAndalus en la Edad Media tardía y hasta los albores del siglo XX, no sólo el Islam y el Judaísmo, sino además cualquier intento de penetración del cristianismo de la Reforma, fueron perseguidos y aniquilados.

Como bien es conocido, la fuerza inquisitorial de la Iglesia Católica en el sudoeste de Europa no tuvo parangón durante un largo periodo de la historia europea, provocando que los movimientos de reforma y renovación cristiana quedaran varados en la cordillera de los Pirineos (Bethencourt, 1997). Aún así, misioneros disfrazados de viajeros, comerciantes, nuevos pobladores, al igual que personal expatriado del aparato diplomático y militar de diversos países de Europa y Norteamérica pudieron conservar, no sin restricciones, prácticas y credos no católico-romanos durante su estadía en España, a cambio de que se mantuvieran en la más estricta reserva (Torres de Castilla, 1883). De aquella época data el primer grupúsculo anglicano en Málaga, que para sepultar honrosamente a sus muertos, tras repetidas interpelaciones a las autoridades locales, fue autorizado a construir una capilla y un cementerio en una colina adyacente a la ciudad rodeada de una espesa naturaleza, manteniéndose alejados de los ojos de los demás conciudadanos (Grace-Hutchinson, 2001). Ciento cincuenta años más tarde, pervive la citada iglesia que ha visto crecer su feligresía en toda la costa andaluza y mediterránea, a raíz de los sucesivos asentamientos de ciudadanos británicos, así como germanos y escandinavos, que ven en el

suroeste de Europa un lugar apetecible donde transcurrir el último tercio de sus vidas (King et al., 2000; Rodríguez et al., 2005).

Pero además de los anglicanos, luteranos y demás cristianismos de la Reforma, han aumentado exponencialmente las congregaciones pentecostales y carismáticas en aquellas áreas de mayor concentración de población extranjera, bien europea, bien latinoamericana, africana o 
asiática $^{2}$. Mientras que surgen nuevos lugares de culto concurridos por nacionales de un mismo o diferentes países que tienen una lengua o lazo común, las congregaciones de españoles y europeos del Norte que ya existían se ven sorprendidas por la incorporación de feligreses de toda suerte de origen étnico y nacional. Todas ellas (evangélicas y no evangélicas, como las adventistas, de Testigos, ortodoxas), las congregaciones cristianas no católicas en España adquieren el estatus de minorías religiosas, abocadas a interactuar con una población española mayoritariamente católica, aunque poco practicante y alejada de muchos dogmas y posturas vaticanas (Pérez-Agote y Santiago, 2005) . $^{3}$ Asimismo, tras la firma de los acuerdos de 1992, el Estado español está llamado a proteger los derechos de las minorías consideradas históricas (musulmanes, judíos y protestantes), estén formadas éstas por ciudadanos nacionales o foráneos (Rozenberg, 1996).

Hacía 500 años que el Estado español no reconocía el estatus de minoría religiosa a ningún grupo ubicado en su territorio. 1492 no sólo rememora el año del desembarco de Cristóbal Colón y su tripulación en tierras americanas, sino además la expulsión de los judíos y la toma del último bastión musulmán en Granada por las tropas de los Reyes Católicos (fíjense en el apelativo), dando lugar a una verdadera limpieza étnico-religiosa. El Quinto Centenario celebrado en 1992 intenta saldar, aunque simbólicamente, una enorme deuda histórica con los miles de judíos y musulmanes, así como de cristianos reformados (o sospechosos de serlo) y sus descendientes, que durante siglos sufrieron persecución y, una vez sometidos, la conversión obligada, el destierro o el martirio (Lewis, 1995). Desde la década de los ochenta, en paralelo al incremento de población extranjera residente en España, se gesta una sociedad más plural en materia religiosa, más tolerante sí, aunque ciertamente no exenta de prejuicios y prácticas discriminatorias.

${ }^{2}$ Según un estudio realizado por el pastor evangélico Bernardo Serrano, a petición de la FEREDE, "Investigación sociológica sobre la integración de los inmigrantes en Andalucía dentro de las comunidades evangélicas" el número de congregaciones se triplicó en la última década, en buena medida por la presencia de población extranjera (Ponencia presentada en el I Congreso Evangélico Andaluz en diciembre de 2006). En total, el autor contabiliza más de 500 iglesias y 30.000 feligreses evangélicos en Andalucía, a los que sumar un número indeterminado de otros cristianos.

${ }^{3}$ Más de la mitad de los españoles (en torno al 60\%) se define como poco o nada religioso, según los resultados de las encuestas, tendencia que ha ido en aumento con el paso de los años. 


\section{Minorías en un país de pluralismo reciente}

El pluralismo religioso en España es aún sólo un esbozo. La aceptación legal y la tolerancia social a la coexistencia de lugares de culto y manifestaciones religiosas diferentes de las católicas no implican que se pueda hablar de cambios en la identidad religiosa nacional. Primero, porque en el cómputo total de la población española todavía son pocos quienes profesan opciones diferentes ${ }^{4} \mathrm{y}$, segundo, porque por estar aparejadas a inmigrantes y minorías étnicas, como los gitanos, las nuevas agrupaciones religiosas son asociadas al desarraigo y provisionalidad (Pérez-Madrid, 2004:32). Además, aunque no cabe duda que la oferta religiosa ha aumentado espectacularmente, hemos de preguntarnos en qué condiciones se encuentra para sobrevivir al proceso secularizador, por un lado, y competir con el catolicismo oficial por conseguir mayores cuotas de reconocimiento, por otro.

Para defender sus modelos explicativos, tanto sobre el impacto de la secularización como sobre la persistencia de las afiliaciones religiosas, diversos autores señalan la necesidad de distinguir entre: a) escenarios de pluralismo elevado, en los que se dan las condiciones para que las ofertas religiosas compitan en condiciones de libre concurrencia $\mathrm{y}$ ganen adeptos $\mathrm{y}, \mathrm{b}$ ) escenarios de pluralismo moderado, donde las iglesias históricas nacionales tales como la española, italiana (Pisati, 2004), sueca (Hamberg y Petterson, 1994) o británica (Davie, 2000), siguen constituyendo un freno importante. Siguiendo esta distinción, Finke y Stark (2003) construyeron la teoría del mercado religioso, pronosticando que mientras en las sociedades de pluralismo creciente se produciría una revitalización religiosa, tanto en el sentido de que los miembros de la iglesia mayoritaria se reafirman, como que los más desencantados son atraídos hacia otras denominaciones que mejor se adaptan a sus necesidades, en las sociedades menos plurales tendría lugar un considerable retroceso de la religión. En contra de esto, diferentes autores han señalado que la mayor oferta no ha revertido en un reavivamiento religioso en muchos países europeos. Por un lado, porque al ponerse en entredicho la verdad hasta entonces absoluta de la Iglesia oficial se cae en una crisis de credibilidad (Berger, 1967) y también a

\footnotetext{
${ }^{4}$ Las estadísticas siguen ofreciendo cifras de que la minoría no católica en España es de apenas el 1,4\% (Pérez-Agote y Santiago, 2005), aunque hay que suponer que los no católicos están subrepresentados en las encuestas porque de muchos inmigrantes y residentes estacionales (como los europeos del Norte) no hay registros y son más difíciles de localizar.
} 
causa de que, en algunos casos como España ${ }^{5}$, la reacción antirreligiosa y anticlerical que se ha gestado durante años de dominio de las iglesias nacionales no permite considerar como deseables otras opciones (Martin, 2005). Por otro lado, se cuestiona la reversibilidad de las tendencias secularizadoras en Occidente (Bruce, 2002) y se apunta a la dificultad de que en determinados países europeos la gente cambie rápidamente de confesión, porque forma parte de su identidad personal y colectiva (Bruce, 1999).

De acuerdo con los argumentos anteriores, todo análisis de los factores que influyen en la mayor o menor práctica y diversidad religiosa en una sociedad ha de tener en cuenta no sólo las condiciones de la oferta sino también la demanda. En el caso español, si bien ésta ha aumentado gracias a la nutrida presencia de ciudadanos originarios de otros países cuyo número crecerá, se estancará o retrocederá según los acontecimientos en los próximos años - no existen indicios de igual tendencia alcista entre la ciudadanía nativa. Respecto a las condiciones de la oferta, si bien a medio y largo plazo las cosas dependerán, entre otros, de la evolución demográfica, en estos momentos la sociedad española se caracteriza por un pluralismo religioso moderado, en el que el catolicismo oficial sigue jugando un papel material y simbólico importante. Éste continúa manteniéndose estrechamente conectado con los centros del poder terrenal, asesorándoles y obteniendo sus prebendas, por ejemplo, a través de un tratamiento especial en temas de impuestos, subvenciones, o enseñanza. Participa, además, activamente en los rituales de la vida cotidiana por solicitud tanto de los más privilegiados (la monarquía, fuerzas armadas, empresarios, personajes públicos) como de los más plebeyos. Poco espacio le resta a las demás confesiones, cuyos deseos de reconocimiento quedan opacados por una más que discutible laicidad del Estado y de la sociedad.

En realidad, el pluralismo moderado legitima la cercanía al poder terrenal de la institución religiosa mayoritaria de un país democrático (pues ahora se basa en la elección, no la imposición), aunque a la par ésta libra una lucha por no perder más espacios de control de los necesarios (en la asignatura de religión en las escuelas, por ejemplo). En cambio, a las demás confesiones, el pluralismo moderado les supone una situación de desleal competencia.

${ }^{5}$ El conflicto entre la Iglesia Católica y el ateísmo y anticlericalismo alcanza su cenit en los tiempos de la segunda República, desembocando en un odio visceral que está en el centro de la Guerra Civil española (1936-1939) (Álvarez, 2002). 
Así las cosas, no todas las confesiones se encuentran en igualdad de condiciones en el contexto de pluralismo moderado dibujado. El sistema español de regulación de las relaciones Estado-confesiones religiosas ha establecido que la pertenencia oficial al club de concurrentes con el catolicismo, únicamente es posible dentro de los acuerdos de cooperación de 1992 entre el Estado y las Federaciones de Entidades Religiosas (musulmanas, israelitas y evangélicas) de probado arraigo histórico ${ }^{6}$. La FEREDE (Federación de Entidades Religiosas Evangélicas de España), instituida en 1986, es la organización que representa a la minoría protestante "autorizada y legitimada" en este país ${ }^{7}$. Incluye a más de mil iglesias en toda España, aunque se comprueba las numerosas ausencias e incorrecciones en sus registros. Mientras los adventistas, por no se sabe muy bien qué criterio, lograron ser incluidos en el listado de entidades de la FEREDE, muchas otras iglesias cristianas, sobre todo aquéllas que han surgido como respuesta a la instalación en España de personas de origen extranjero, no figuran. Otras muchas que sí figuran, ya no existen o se han fragmentado (Briones et al. 2005).

El mundo evangélico que forma parte de la FEREDE compone una Minoría (en mayúscula), gobernada por las denominaciones de tendencia no (neo)pentecostal y lideradas por españoles, dentro de la cual y fuera de ella existen otras minorías (en minúscula) sin apenas voz ni legitimación. Para ser más precisos sobre la distinción entre minorías mayoritarias y minorías minoritarias (sin poder, prestigio ni legitimidad) cabe subrayar que, aunque las minorías comúnmente se reconocen en términos numéricos o jurídicos, aparentemente objetivos, existen además criterios sociológicos y una gran dosis de subjetividad en su determinación y clasificación.

Como primer apunte para demostrar que los criterios estadísticos no están exentos de subjetividad, hay que tener en cuenta que el punto de comparación lo establecen los actores. Se puede ser minoría numérica con respecto al país de incorporación pero mayoría respecto al de origen o a la implantación de una corriente a escala mundial (argumento esgrimido por agrupaciones como la Iglesia Bautista, los Testigos, las

${ }^{6}$ Además del Estado, las Federaciones firman acuerdos de cooperación con los gobiernos regionales, que garantizan el reconocimiento y la aplicación de derechos mediante ayudas económicas. El acuerdo de la FEREDE con el gobierno regional andaluz es de 2006.

${ }^{7}$ www.ferede.org 
Asambleas de Dios). Esta relatividad en las asignaciones tiene repercusiones en la configuración del grupo y las relaciones que establece con su entorno, como queda demostrado en el estudio de Yang y Ebaugh (2001) respecto a dos iglesias chinas en los Estados Unidos, y como veremos en el caso de la iglesia anglicana en Málaga. Otro ejemplo lo constituye el caso de la FEREDE, en la que si el factor determinante fuera la representatividad numérica, debiera estar gobernada por los gitanos pentecostales o por los Testigos de Jehová, en caso de ampliarse a otras corrientes cristianas no evangélicas. En cambio, el control de esta instancia recae en minorías numéricas (de Bautistas, Hermanos, y demás) que con la autoridad y los recursos que acumulan acrecientan su presencia.

En segundo lugar, cabe recordar que sobre los criterios jurídicos se ha resaltado ya la importancia del registro y el establecimiento de protocolos y canales institucionales para el contacto entre grupos. "Si no estás, no existes, por tanto, no tienes derecho al reconocimiento de tus derechos y especificidades". Esta situación afecta, en especial, a los cientos de nuevas congregaciones o grupos cristianos no formalizados que operan en España desde el advenimiento de la más reciente inmigración. Muchos de ellos no están registrados, achacándose, unas veces, a su propia falta de interés, otras veces, a las dificultades de cumplir con los criterios de admisión, que pueden considerar algunas prácticas inaceptables o, finalmente, por trabas burocráticas, económicas o lingüísticas, aspecto señalado especialmente por los pentecostales africanos de Málaga. Como consecuencia de estas omisiones, a los pastores y ministros de estas nuevas iglesias no se les reconoce su calidad de personal al servicio de la comunidad y, por lo tanto, sus visados, exenciones fiscales y otro tipo de ventajas, son rechazados.

Por último, en cuanto a los criterios sociológicos para la caracterización de las minorías, se desea remarcar aquí la subjetividad que entraña y las contradicciones que subyacen a estos procesos de inclusión-exclusión, según se explica a continuación.

1) Si una minoría lo es frente a una mayoría, generalmente porque carece de, o posee en menos cantidad o calidad, una característica de referencia, qué sucede cuando esta característica es la religiosidad. ¿A quién se debería considerar más minoría "religiosa", a quien más o a quien menos cree y practica, si nos atenemos al elevado grado de 
extrañamiento de las instituciones y dogmas religiosos que manifiestan muchos católicos en España? ${ }^{8}$.

En contraste con la baja intensidad de la religión oficial, los resultados de una encuesta a inmigrantes no comunitarios en Andalucía, realizada en 2002 (Pérez y Rinken, 2005), mostraron que muchos cristianos no católicos consideran que la religión está por encima de todas sus otras prioridades (familia, trabajo, amigos). Probablemente, el carácter carismático de muchas de estas congregaciones herederas de la Reforma, que se sienten en constante reavivamiento y exigen gran involucración de sus fieles, contrasta con la rutinización de las prácticas y la enculturación de las creencias que caracteriza a gran parte de la feligresía católica, o anglicana.

2) Un segundo criterio de distinción de las mayorías respecto a las minorías es la percepción de la diferencia o similitud que se guarda entre ellas. Así, algunos grupos, pese a estar regidos por reglas y rutinas diferentes - incluso divergentes en algunos puntos -, no se consideran ellos mismos ni son considerados por el resto de la colectividad como "minorías", en cambio otros sí. La distancia social se construye sobre una base actual o histórica de factores religiosos (antagonismos teológicos y dogmáticos), territoriales (que determinan el "arraigo" de un grupo) y sobre todo étnicos (aún siendo de "los nuestros", sus prácticas culturalmente marcadas y su racialidad les separa), como se verá al tratar de las particularidades de, y las relaciones entre, pentecostales africanos, anglicanos anglosajones y españoles.

De todo lo anterior se concluye que las jerarquías y desigualdades se establecen no sólo entre las minorías y las mayorías, sino también al interior de cada una de éstas. Esto, por un lado, impide que se consoliden alternativas religiosas sólidas al catolicismo mayoritario, por otro lado, desincentiva a los individuos a mantener o adoptar formas religiosas consideradas "minoritarias" en el proceso de convergencia con la sociedad española. Una consecuencia sería que, al contrario de lo esperado, las nuevas formas de religiosidad aportadas por la población con experiencia de vida en el extranjero no logran estructurar una sociedad de pluralismo religioso elevado. Con todo, desde su posición privilegiada o desfavorecida, es innegable que las iglesias que representan a minorías étnicas y religiosas cumplen unas

8 Entrevistado: "Desde el punto de vista de los números, la iglesia católica no es minoritaria, pero desde el punto de vista de la efectividad real, creo que es minoritaria. Con eso quiero decir que son pocos los católicos que viven como católicos en el mundo". 
funciones específicas e insustituibles entre sus correligionarios. A través de los dos ejemplos siguientes que ilustran sólo una pequeñísima porción de la heterogeneidad del mundo cristiano evangélico, se busca demostrar esta interrelación entre función interna y posición social, característica de las congregaciones formadas por grupos distintivos.

\section{Una Congregación Anglicana Angllosajona y una Congregación Pentecostal Africana}

Las dos iglesias de las que se tratará a continuación son representativas de corrientes distintas dentro del protestantismo internacional pero tienen en común el hecho de utilizar el inglés como lengua de comunicación y ser étnicamente homogéneas en su composición.

El trabajo de campo en el que se encuadra el estudio de estos dos casos fue realizado entre 2005 y 2006, consistente en la observación participante, la conducción de grupos de discusión y la realización de entrevistas abiertas a informantes clave y feligreses. El seguimiento de las congregaciones fue complementado con el de las actitudes de los andaluces nativos respecto a las minorías religiosas, formando parte de un proyecto global sobre Inmigración y Religión en Andalucía.

\section{Caracterización}

Las dos congregaciones están ubicadas en la provincia de Málaga, dentro de Andalucía. Málaga ofrece la mayor diversidad de iglesias cristianas no católicas de esta Comunidad Autónoma (o estado) al convertirse en provincia destino, tanto de jubilados del Norte de Europa, como de inmigrados de países menos favorecidos y de emigrantes españoles retornados. De las dos congregaciones, una representa el evangelismo de primera generación, el de la iglesia anglicana, la otra se mueve en la tendencia pentecostal independiente, de más reciente expansión. Les une el hecho de que ambas son congregaciones formadas en su casi totalidad por extranjeros, existiendo una acusada homogeneidad en el origen nacional. Mientras que la iglesia anglicana es frecuentada en su mayoría por ciudadanos británicos, la iglesia pentecostal estudiada reúne a ciudadanos procedentes de diversos países de África, aunque predominan los nigerianos.

Los orígenes y características de las denominaciones evangélicas presentadas son distintos. La iglesia anglicana de Málaga forma parte del 
entramado religioso que ha acompañado la expansión británica por el mundo, a semejanza de la iglesia católica, ofreciendo servicios para sus fieles, oriundos de "la madre patria" o súbditos de la corona, que se hallan esparcidos por los cinco continentes. La iglesia actual parte de una importante comunidad británica formada por residentes y transeúntes en Málaga ya desde las postrimerías del siglo XVIII. Esta comunidad se logra aglutinar en torno a un cementerio protestante de principios del siglo XIX en cuyo recinto finalmente pudo construirse la actual iglesia, convirtiéndose en lugar de culto anglicano desde 1891.

La historia de la iglesia pentecostal africana visitada en Málaga es mucho más corta. Arranca del año 2000, cuando un pastor nigeriano que ya había abierto dos iglesias más en España, reunió a un grupo de fieles en Málaga en un pequeño local del centro de la ciudad. Rápidamente la comunidad creció tanto que fue necesario trasladarse a otro lugar más amplio que permitiese oficiar el culto $\mathrm{y}$, a la vez, disponer de diferentes espacios para las oficinas del pastor y sus diáconos, una guardería y aulas de estudio. En ese nuevo local es donde se contacta con esta congregación que se define independiente, sin explícitas conexiones con otra iglesia nigeriana ni de otro país africano.

Cabría señalar otros puntos cruciales de distinción. En la congregación anglicana abundan las personas mayores, superando ligeramente en número las mujeres. Este perfil se asemeja al de la feligresía habitual de las iglesias católicas. En cambio, la congregación pentecostal africana está formada mayoritariamente por hombres jóvenes o de edad media, con nula existencia de mayores, y un reducido número de mujeres y niños que se prevé aumente a medida que prosperen las reagrupaciones y se formen familias.

Aquí reside, además, otra notable diferencia, a saber, que los anglicanos acuden a la iglesia generalmente en pareja mientras que los pentecostales africanos lo hacen solos, acompañados de otros varones. Esta situación es reflejo de un estatus legal y socioeconómico diferente. La nacionalidad británica de los anglicanos les convierte en ciudadanos comunitarios con los mismos derechos y deberes que los españoles, mientras que los africanos, de cualquier nacionalidad, se mantienen en buen número todavía en la ilegalidad documentaria o, si tienen los papeles en regla, permanecen en situación de gran inseguridad e inestabilidad económica y jurídica. En concreto, mientras que muchos anglicanos son propietarios de casas en Málaga y sus contornos, que han comprado con sus ahorros o con la venta de otras propiedades, y viven de sus jubilaciones o están ocupados en negocios propios (de inmobiliaria, 
enseñanza, restauración y demás), los pentecostales africanos viven mayoritariamente de alquiler, a menudo en condiciones de hacinamiento y subsisten con trabajos esporádicos o mal pagados, sucios, onerosos, independientemente de su nivel de formación, según ellos mismos explican.

Con todo, es importante especificar que aunque no concuerde con la figura que se tiene de los británicos, ambos flujos migratorios, en mayor o menor medida, responden a un determinante económico. Es sabido que la principal razón que los africanos tienen para decidir migrar a Málaga es la búsqueda de un trabajo mejor remunerado, que les permita acceder a un nivel de vida aceptable para ellos y sus familias. Pero la migración de retiro del Norte de Europa también encierra un factor de atractivo económico. Málaga, además de ofrecer un clima cálido durante la mayor parte del año, presenta la ventaja añadida de tener un menor costo de vida. Esto permite a los retirados disfrutar de una calidad de vida parecida, o de repente mejorarla, respecto a la que tenían en casa.

Un último apunte en la caracterización de ambas congregaciones es que aunque los anglicanos constituyen una minoría religiosa en Andalucía, en general esto no les plantea ningún problema porque se saben miembros de una religión mayoritaria en su lugar de origen y además cuentan con el reconocimiento de ambos Estados (conformando una minoría mayoritaria) ${ }^{9}$. Los pentecostales, por el contrario, son una minoría aquí y en buena medida también en sus países, donde deben compartir - y competir por - el espacio físico y simbólico con otros cristianos (católicos, bautistas, etc.), con musulmanes y con animistas ${ }^{10}$ (conformando, por tanto, una minoría minoritaria). Esta condición en número y poder, según entendemos, les conduce a la necesidad de

9 Resulta interesante traer aquí las confesiones de varios anglicanos entrevistados que coincidieron en apuntar, no obstante, un sentimiento de amenaza a su condición de mayoría religiosa en el país natal:

"Los ingleses, yo creo, han venido aquí (España) para escaparse de los musulmanes, porque allá (Reino Unido) hay muchos, allá hay pueblos enteros que tienen sus mezquitas, sus colegios, en las calles". [...]

"En Inglaterra hay un problema con los musulmanes. Allá los musulmanes quieren convertir a todo el mundo. Aquí no veo eso, aquí no es evidente. Aquí a España sólo venimos familias inglesas ancianas, gente retirada, en cambio, a Inglaterra van familias musulmanas jóvenes. Además tienen muchos niños. Una joven me decía: "ustedes tienen a su reina, pero nosotros tenemos a su país" y es verdad. Años atrás una de cada diez personas era musulmana, ahora es 5 de cada 10." sincréticas

${ }^{10}$ Practicantes de las religiones africanas tradicionales o en sus formas 
protegerse de los ataques externos haciendo causa común. Tal vez por eso hallemos pocos nigerianos fuera de las iglesias pentecostales africanas en Málaga, que han crecido en número y compiten entre ellas por ganar adeptos entre connacionales. Por el contrario, a pesar de las facilidades y el prestigio añadido, la mayoría de británicos, jóvenes y mayores, no siente la necesidad de agruparse en congregaciones anglicanas o de otra denominación, y en todo caso, si se agrupan lo hacen en torno a otro tipo de formas de asociación (clubes deportivos, culturales, políticos).

\section{Dinámicas internas en las congregaciones}

La congregación anglicana anglosajona y la pentecostal africana presentan distinta organización y orientación. Al pastor nigeriano de la iglesia pentecostal la congregación le reconoce una autoridad religiosa, que es fruto de su propio carisma y no de su designación por jerarquía religiosa alguna. De hecho él es el fundador de la iglesia y con sus discípulos (o diáconos) ha establecido las normas que la rigen. Además de actuar como consejero espiritual, tiene la potestad de influir y fiscalizar la vida pública $\mathrm{y}$, de considerarse necesario también, la vida privada de sus miembros. Funciona una suerte de control social, no sólo por parte de los líderes de la congregación sino entre los propios feligreses, sobre la vida de los demás, afanándose por demostrar que son verdaderos cristianos en su vida dentro y fuera de la iglesia. De ahí que espontáneamente en sus discursos todos insistan en la obligación de no pecar, entre otros, absteniéndose de la ingesta de bebidas alcohólicas, de fumar $y$, por supuesto, de tener relaciones sexuales fuera del matrimonio.

En cambio, en la congregación anglicana los pastores son clérigos ordenados, procedentes del Reino Unido o Norteamérica, que cambian de parroquia cuando sus superiores se lo exigen o a propia petición. Aquí la autoridad del pastor se circunscribe a los asuntos espirituales, estando considerado por los demás como un miembro más, aunque profesionalizado, de la comunidad religiosa. El pastor anglicano es asistido en sus funciones por un grupo de laicos comprometidos libremente con la parroquia, quienes a menudo logran gran protagonismo en las liturgias. La vida que lleven los feligreses fuera de la congregación no suele ser asunto de escrupulosa atención, los preceptos religiosos y 
morales se viven de forma más relajada. ${ }^{11}$ Facilita esta situación el hecho de que los anglicanos apenas pasen un par de horas juntos a la semana, mientras que los pentecostales celebran cultos extensos, además de otras actividades asociadas, que les ocupan prácticamente todo el domingo y muchos otros momentos durante la semana.

Los anglicanos otorgan mayor importancia a las actividades caritativas y al compromiso social que a vigilar férreamente su comportamiento. Por esta razón, la mayoría de sus miembros se encuentran envueltos en acciones de voluntariado. Pero esto no debe interpretarse como producto exclusivamente de una diferente vocación, sino de la distinta situación socio-económica de las dos comunidades. La precariedad económica de la congregación pentecostal limita notoriamente la acción que ésta desearía desarrollar en el campo de lo social. Entre sus planes está el constituir organizaciones de ayuda sanitaria y educativa, dirigidas a cubrir las necesidades de los más necesitados. Empero, este discurso se aleja de la cruda y prosaica realidad, porque actualmente la iglesia no cuenta apenas con ingresos económicos suficientes como para autoabastecerse, ni qué decir como para realizar este otro tipo de acciones.

Un segundo aspecto a contrastar son las razones que motivan a los británicos y nigerianos a incorporarse a sus respectivas congregaciones.

La iglesia pentecostal africana permite a sus feligreses sentirse parte de una comunidad en donde reproducir libremente las costumbres y tradiciones propias de su país de origen. Éstas abarcan tanto formas de vestir, alimentación, lengua y música, como prácticas de género y relaciones de poder dentro del grupo. La generación de este espacio, en donde no sólo se acepta estas prácticas sino que incluso son apreciadas y consideradas dadoras de estatus por encima del menosprecio que sienten hacia sus costumbres y hacia sus personas en la sociedad receptora, hace atractiva la participación de los africanos residentes en Málaga. Pero ¿acaso esto no podría lograrse a través de otro tipo de organización?. ¿Por qué entonces prima una orientación religiosa?.

Es evidente que la iglesia cumple la función de lugar privilegiado de socialización y de acogida. El anhelo de sentirse aceptado

11 Informante clave: "Venir de países donde la religión se vive de una forma más legalista, más normativa... (es complicado). Ellos están acostumbrados a que el pastor les diga lo que tenían que hacer. Pero yo soy una persona más del otro bando, pienso que la responsabilidad es de cada uno, yo no puedo asumir responsabilidades por otras personas. Esto ha causado un choque cultural." 
y protegido, sobre todo entre los recién llegados a Málaga, es uno de los principales factores que motivan el acercamiento a la iglesia. En la congregación se van construyendo y consolidando redes sociales que permiten satisfacer tanto las necesidades materiales como psicológicas de los feligreses, facilitándoles en la medida de lo posible la búsqueda de empleo, vivienda temporal, alimento, información jurídica y soporte afectivo. En este sentido, la iglesia aparece como lugar confiable puesto que se sostiene sobre normas morales estrictas y hay una autoridad y responsabilidades visibles: "con las cosas de Dios no se juega".

Para entender, además, porqué la mayoría de nigerianos en Málaga se organiza en torno a iglesias hay que dirigir la atención hacia sus lugares de origen, constatando que allí también las iglesias tienen una gran actividad y abundante feligresía. Muchos de ellos solían asistir a iglesias protestantes de diverso signo, con las cuales incluso siguen manteniendo estrecho contacto desde afuera y a través de sus familias que todavía las frecuentan. En resumen, la costumbre, la necesidad real de continuar fortaleciendo el "yo" espiritual, la atracción del ritual y la comunión con los demás, la oportunidad de encontrarse con amigos y conocidos e intercambiar informaciones y recursos, entre otras, son razones que generalmente hallamos de forma combinada en cada uno de nuestros informantes.

Por su parte, la iglesia anglicana también brinda a sus miembros la oportunidad de acceder a una comunidad en donde reproducir sus códigos y prácticas culturales. Si bien, por el contrario, no se ven en la necesidad de hacer frente a estigmas sociales, es importante para ellos frecuentarse para consolidar el sentimiento de comunidad expatriada. Existe una estrecha vinculación entre la iglesia anglicana y la identidad nacional, de ahí que la asistencia a la iglesia en la emigración se constituya en elemento clave en la reafirmación de una identidad colectiva. Esto ocasiona que la religiosidad de los anglicanos sea una práctica más relacionada a la cultura y tradición inglesa que a lo meramente espiritual. Como suele producirse en todo proceso migratorio, una vez que el individuo se encuentra fuera de su país natal, a la vez que aflora la nostalgia y se imagina la patria, se reactiva el sentimiento de pertenencia a la nación. Por esta razón, las actividades que organizan y celebran los anglicanos son de tipo social y no de índole espiritual, como la fiesta de San Jorge, que se asocia más a un pasaje épico que religioso. Estas actividades ayudan a nutrir y fortalecer la solidaridad orgánica entre sus miembros. Ésta se plasma en ayudas puntuales en alguna labor, facilitar recursos y contactos y hacer la vida más fácil a los recién llegados que no manejan el español. De este modo, la congregación 
también es útil a las necesidades materiales de sus miembros e incluso pueden expandir sus servicios hacia fuera de la comunidad.

\section{Relaciones interétnicas e interreligiosas}

Las dos iglesias reciben en sus cultos y demás eventos a personas de otras vertientes cristianas. Lo importante, aseguran, es que quienes con ellos comulguen crean en la Trinidad (lo que descartaría a los cristianos no evangélicos). De esta manera, permiten participar en el culto a cristianos de otras denominaciones que también hablen el inglés aunque no sea como lengua materna.

El idioma cumple en ambas congregaciones una función similar. Es el vehículo que aglutina a creyentes de diversos orígenes nacionales y, paralelamente, limita el acceso a sus cultos a quienes no lo manejan, en realidad a la mayoría de la sociedad andaluza. Con todo, a pesar de que ambas iglesias realizan el culto en inglés, a cada una acuden personas de diferente procedencia. En la iglesia anglicana participan miembros que provienen principalmente del Reino Unido, los Estados Unidos, Canadá, Australia y Sudáfrica, así como personas de otros países europeos que tienen mayor conocimiento del inglés que del español. Incluso, llegan a participar en ella, aunque minoritariamente, nigerianos que en su país de origen solían asistir a la iglesia anglicana. Por el contrario, al culto

pentecostal acuden solamente personas de procedencia del África anglófona: de Nigeria principalmente y algunos pocos de Camerún y Etiopía. Del mismo modo que a la mayoría de fieles anglicanos les une un origen común blanco y anglosajón, a los pentecostales les une su origen africano que les hace sentirse racial y culturalmente diferentes en Europa.

Tras lo anterior cabría preguntarnos porqué, si ambas iglesias ofrecen el culto en inglés y tienen identidades propias, algunos nigerianos asisten al culto anglicano y, en cambio, no hay ni un sólo anglosajón que asista al culto nigeriano. Una explicación ya se ha apuntado, al mencionar la posición menos valorada que tiene la cultura africana en comparación a la anglosajona. Otra razón se debe al carácter universal de la Iglesia Anglicana (extendida por los cuatro continentes desde hace siglos) frente al particularismo de la iglesia pentecostal de origen africano. Los nigerianos que atienden el culto en la iglesia anglicana de Málaga ya asistían antes a esta misma iglesia en su ciudad o pueblo de origen, no debiéndonos extrañar entonces que vuelvan a 
visitarla una vez en Europa ${ }^{12}$. Los anglicanos, sin embargo, desconocen completamente las fórmulas en que se manejan estas nuevas iglesias pentecostales independientes. En tercer lugar, la asistencia de algunos nigerianos a la iglesia anglicana de Málaga parece estar fundamentada en un interés particular por entablar un contacto más estrecho con ciudadanos comunitarios a fin de obtener determinadas ventajas materiales. El mismo interés por parte de los anglicanos no se puede deducir.

Resulta destacable que, tanto entre los feligreses de la iglesia anglicana como entre los de la iglesia pentecostal, se hallan orígenes religiosos familiares diversos y desplazamientos entre denominaciones en el curso vital según las circunstancias ("intercomunión litúrgica"). En el caso de los anglosajones se hace más notorio por el hecho de que muchos de ellos han vivido por periodos de su vida en países de los cuatro continentes, teniéndose que adaptar a la oferta religiosa existente. Los nigerianos de la iglesia pentecostal, tal vez también por su juventud, no poseen tan dilatada experiencia de vida internacional, aunque, como algunos de ellos confesaron, tienen intención de proseguir su carrera migratoria hacia otros países de Europa, América del Norte e incluso Oceanía. En consecuencia, es esperable que continúen en el futuro el periplo de desplazamientos entre denominaciones e iglesias, acomodándose a las circunstancias personales y del contexto.

Esta diferencia entre el aparente cierre en el que se encuentra la feligresía de la iglesia pentecostal africana en comparación al cosmopolitanismo de la feligresía anglicana, se extiende al ámbito de las relaciones entre iglesias y a la inclusión en los órganos representativos de los cristianos evangélicos y católicos en la ciudad. El pastor de la iglesia pentecostal apunta que mantiene contactos con las Asambleas de Dios y con la iglesia Bautista con la que espacialmente colinda. Sin embargo, no hemos tenido noticias de que se hayan celebrado cultos conjuntos ni actividades similares porque, como señalan, no han sido invitados. Por el contrario, la iglesia anglicana acostumbra anualmente a disfrutar de más de una jornada de confraternidad con otras iglesias, en especial con la católica, con la que comparte un espacio común en el centro ecuménico Lumen Dei.

Los propios anglicanos admiten que su iglesia está más próxima a la Iglesia Católica que al resto de las vertientes cristianas. No obstante

12 Con todo, un informante anglicano se apresura a señalar que: "la iglesia anglicana en África es más conservadora", argumento que sirve de legitimación de posteriores fricciones. 
este acercamiento entre la Iglesia Anglicana y la Católica, las diferencias e incluso fricciones asoman. El desacuerdo principal estribaría en el mayor liberalismo de la anglicana, que permite la ordenación de mujeres sacerdotes y hasta que homosexuales celebren homilías. La cuestión del protagonismo femenino anglicano ha llevado a situaciones de fuerte tensión con algunas parroquias católicas hasta el punto de interrumpir la celebración de misas conjuntas ${ }^{13}$.

Fuera de la representación institucional, aparte de unos pocos nigerianos que asisten a la iglesia anglicana, como vimos, otros nigerianos pentecostales manifestaron haberse llegado previamente a la iglesia Católica en España, a donde acudieron en busca de ayuda de carácter asistencial. Por un lado, muchos comentan haber tenido contacto en su país con la iglesia católica, tan extendida o más que la anglicana por el mundo. Por otro lado, al estar integrada en su mayoría por personas de origen español, posee redes más amplias y de mayores recursos económicos que la iglesia pentecostal nigeriana, con una red de parroquias que se extiende a todos los pueblos y ciudades de la geografía.

En resumidas cuentas, la trayectoria de una parte de los africanos discurre de la siguiente forma: en un primer momento, acercamiento a las iglesias formadas por españoles nativos o por personas de distintos países, más tarde, replegamiento en iglesias propias. Las iglesias de feligresía mixta facilitan, en primera instancia, el proceso que conduce a la incorporación de los inmigrantes en la sociedad receptora, dado que los miembros españoles y extranjeros mejor ubicados social y económicamente pueden echar una mano en la obtención de empleo y papeles. En segunda instancia, sin embargo, parece que las iglesias étnicas cumplen un papel en la socialización de los inmigrados que las mixtas no logran canalizar. Interrogados sobre este punto, muchos afirman que prefieren asistir a las denominaciones evangélicas propias, dada su dinámica más emotiva, más cercana a sus experiencias anteriores. Una vez satisfechas las necesidades básicas, los recién llegados prefieren socializarse con iguales en ambientes lúdicos y de oración que les sean familiares. En la liturgia africana, además, se

13 Informante clave: "Las relaciones con la iglesia católica se trastocaron porque vieron a Kate con la túnica, como ella es lay reader, entonces el cura (católico) le pidió que se retirara. Decía: "hay una mujer pastor en nuestra iglesia". Nosotros le explicamos una y otra vez que no era un pastor. Entonces las personas que iban a la iglesia se preguntaban porqué la iglesia católica no permitía eso también. No es cuestión de prejuicio, sino es la forma que la iglesia católica entiende las cosas. En su parámetro no entienden que una mujer pueda presidir un culto". 
celebra una experiencia migratoria común que se plasma en los cánticos a Dios y a su hijo, lanzando implícitamente un grito de protesta contra las adversas condiciones en las que se hallan en Málaga, toda vez que de gratitud por haber alcanzado el sueño de pisar Europa.

Los anglicanos, por el contrario, no acuden a otra iglesia que no sea de habla inglesa y representativa de una corriente del cristianismo, tradicional de su área de procedencia: anglicana, presbiteriana, metodista. Primero, porque no suelen buscar asistencia económica en las iglesias y, segundo, porque en sus elecciones priman las redes de connacionales y la cercanía residencial.

Respecto a la participación de españoles en estas iglesias, señalar, que la falta de feligresía autóctona se experimenta de forma diferente en la congregación anglicana que en la pentecostal. Esta situación es motivo de preocupación principalmente entre los dirigentes pentecostales, porque para ellos la difusión de su iglesia y doctrinas es crucial como vía de su sostenimiento y legitimación. Concomitantemente, consideran importante contar con feligreses españoles y de otras nacionalidades no africanas, para expandirse y lograr una mayor aceptación social. No obstante, se establece una tensión entre los predicamentos y las prácticas cotidianas. Los líderes de la congregación, si bien son conscientes de que en muchas ocasiones sus prácticas les condenan a la segregación, a pesar de ello no toman serias medidas para contrarrestar esta situación. Según entendemos, los pastores temen realizar una gran transformación interna que les lleve a perder aquellos rasgos propios que son, en definitiva, lo que mueve a la mayoría de sus feligreses a reunirse en torno a una congregación marcadamente africana.

Por su parte, los anglicanos se manifiestan más cautos a la hora de propagar las bondades de su iglesia. En realidad, sus líderes no buscan convertir a nadie, si no recibir y servir espiritualmente a los anglicanos que llegan a residir en la zona. De ahí que se trate de una comunidad religiosa poco numerosa con bajo incremento a lo largo de los años. Entre sus objetivos no está el de difundir su religión, ya que prefieren que las personas que se acercan lo hagan por propia iniciativa y afinidad cultural. Tienen poco o nulo interés en incidir en la sociedad andaluza, si no es por el ejemplo de mayor tolerancia del que hacen gala, conservando intactas sus características de iglesia anglosajona internacional.

Un ejemplo lo constituyen los matrimonios de anglicanos y pentecostales con españoles. Estos matrimonios son más numerosos 
entre los pentecostales que entre los anglicanos, por una serie de razones. La edad media más joven de los africanos y el hecho de llegar mayoritariamente solos a Málaga les hace más proclives a buscar pareja. Asimismo, los africanos se muestran más interesados por casarse con alguien poseedor de una nacionalidad comunitaria que los británicos. Si lo consiguieran, lograrían disminuir la discriminación racial de la que son objeto, así como obtener la autorización incondicionada para su residencia. Con la residencia comunitaria acceden a toda una serie de derechos que antes les eran negados, tales como: obtener un trabajo en la economía formal o mejor remunerado, la posibilidad de abrir su propio negocio, acceder a crédito bancario, conseguir un alquiler de piso en condiciones, entre otros.

Una vez llevado a cabo el matrimonio, los varones pentecostales nigerianos estimulan a la conjugue a acompañarles al culto dominical. Para los miembros de esta congregación es muy importante introducir paulatinamente a la esposa a la dinámica de la iglesia por el gran valor que se le asigna a la unidad de la familia. Si bien no le instan a convertirse, sí le piden que se incorpore con su presencia a la comunidad religiosa. No obstante, esto no siempre se consigue y a algunos feligreses sus esposas no les acompañan, bien porque son católicas practicantes, bien porque no tienen interés por asistir a ninguna iglesia.

Entre los anglicanos casados con españoles o personas de otras nacionalidades se observa otro patrón. Si bien al inicio puede existir un interés del anglicano por introducir a su conjugue en la comunidad religiosa, a la primera muestra de desinterés o rechazo no suelen insistir en su petición, según dicen, argumentando respetar la libertad de sus seres queridos. Defienden una postura de absoluta libertad religiosa en el hogar que lleva a que muchas parejas e hijos de los feligreses no les acompañen nunca al culto dominical.

\section{Las iglesias en el proceso de incorporación a la sociedad receptora}

Por el uso de una lengua extranjera, el particularismo y la homogeneidad interna de sus congregaciones, así como por la utilidad que sus feligreses le encuentran, tanto la iglesia anglicana anglosajona como la pentecostal africana en Málaga podrían ser definidas como 
enclaves étnicos ${ }^{14}$, que ayudan a la superación de obstáculos, toda vez que limitan la interacción con los miembros de la sociedad mayoritaria. El hecho es que, a pesar de que el discurso de los líderes de las dos iglesias sea de carácter universalista: "Dios es único y el mismo para todos" o "esta iglesia está abierta a todos, blancos y negros", el uso del idioma y otras prácticas culturales inhiben la participación a los españoles y personas de otras comunidades étnicas.

Desde otra perspectiva, empero, la iglesia como enclave étnico opera a modo de plataforma para la integración social de sus feligreses, aunque lo es de forma diferenciada para las dos comunidades. Los anglicanos, mayoritariamente jubilados sin demasiados problemas para mantener una vida digna en España, viven por deseo propio aislados de la sociedad nativa en su retiro vacacional: residen en urbanizaciones costeras ocupadas por compatriotas o en lugares retirados del interior de la provincia con escaso o nulo contacto con andaluces de origen. En este contexto la iglesia se erige en un lugar privilegiado de reunión en el que mantener una relación al menos institucional, además de una cercanía espacial, con la sociedad receptora. Teniendo en cuenta la provisionalidad de la residencia de muchos anglicanos en la provincia, con frecuentes idas y vueltas al país de origen y retorno definitivo cuando la salud empeora ostensiblemente, la iglesia representa una suerte de comunidad transnacional con un ojo puesto aquí y otro allá, aprovechando lo más valorado de cada ubicación: allá la familia, aquí el entorno.

Con todo, cabe resaltar el papel fundamental que desempeñan las numerosas actividades de confraternidad que organizan los anglicanos, con el fin de recaudar fondos para el mantenimiento del cementerio inglés y el templo u otros fines. Al tratarse de actividades no religiosas, los anglicanos se ven en la libertad de adoptar algunos elementos de la sociedad malagueña, como en los almuerzos, donde se suele ofrecer paella (el plato más internacional de la comida española), vinos y tapas. En estas actividades participan un gran número de feligreses anglicanos, al igual que algunos miembros de la sociedad española que por propia iniciativa se acercan esporádicamente a la iglesia, ya sea por estar de

${ }^{14}$ Se utiliza aquí la acepción de "enclave étnico", en el sentido dado por autores como Portes (1987) para explicar el éxito de algunos grupos de migrantes en la formación de economías, en principio al margen de los mercados de trabajo nativos. En este caso, el enclave étnico se daría dentro de la comunidad religiosa que se aparta de la oferta religiosa exterior porque por sí misma satisface las necesidades materiales, sociales y espirituales de sus miembros. 
acuerdo con los preceptos religiosos, ya por curiosidad o amistad o con el simple propósito de practicar el inglés ${ }^{15}$.

Es obvio que los miembros de la congregación anglicana, al ser trabajadores independientes o pensionistas, rentistas o jubilados, tienen una mayor capacidad adquisitiva y compatibilidad horaria. Para contrarrestar el hecho de no percibir ingresos por parte de la Iglesia Anglicana de Inglaterra $u$ otras instituciones, organizan estas actividades internas para recaudar fondos que destinan en parte a fines benéficos. Por ejemplo, los entrevistados afirman que parte del monto que se recauda en los cultos dominicales se deriva a Organizaciones no gubernamentales españolas dedicadas a ayudar a los niños huérfanos. También de manera esporádica ayudan a españoles desempleados o sin techo que se acercan a pedir asistencia. Bajo estas circunstancias, es lógico que los anglicanos perciban una mayor aceptación por parte de la sociedad receptora que los africanos pentecostales.

En el caso de los pentecostales africanos, la iglesia opera como plataforma de incorporación más profunda y duradera que la congregación anglicana. No cabe duda de que la congregación estudiada facilita la adquisición de un capital social, necesario para abrirse camino en el nuevo entorno $y$, adicionalmente, con su retórica sobre la autenticidad, la universalidad y el sentimiento de "ser los elegidos" eleva la autoestima de la comunidad en su conjunto y de los individuos, migrantes de primera generación ${ }^{16}$. Así pues, la iglesia mantiene un discurso de apertura y al mejorar la salud material, espiritual y emocional de sus miembros, se puede sostener que les ayuda y prepara para su vida en un nuevo territorio.

No obstante, a pesar de no buscar la segregación como en el caso anglicano, por el hecho de participar en una iglesia minoritaria y con poco prestigio atribuido por parte de la sociedad receptora, la integración se realiza a un estrato más bajo dentro de la escala social local. Desde el punto de vista interno, los prejuicios o, más explícitamente como dirán

${ }^{15}$ Entrevistada: "Un tiempo venían un grupo de españoles a escuchar el culto dominical. Por ellos se hacía en inglés y en español. Pero me tuve que ir a Inglaterra en el verano y, lamentablemente, cuando volví ya no estaban. Se hacía un culto muy agradable, eran españoles anglicanos. Ellos querían ser anglicanos. Incluso una de las mujeres quería ser pastora anglicana. Entonces ella fue a Inglaterra a prepararse. Ella habló con Jennifer para que la ayudara, pero no pudo, porque su inglés era muy malo."

16 Martin (2005) verbaliza este proceso de paso de la discriminación y exclusión a la modernidad a través de la comunidad pentecostal. 
los propios feligreses, el racismo de la sociedad española es lo que impide que personas de la sociedad mayoritaria y de otros grupos evangélicos se acerquen a ellos y a sus templos, o que ellos tengan cabida en las instituciones de la sociedad receptora. Desde el punto de vista externo, empero, sus actividades, sus costumbres, pueden resultar menos atractivas a los ciudadanos nativos que no gustan de pasar tan largas horas entre cánticos y rezos.

Asimismo, debido a la irregularidad documentaria y a los salarios más bajos que perciben los africanos, estos mantienen una economía de subsistencia y su ahorro se canaliza a través de remesas a sus familiares en los países de origen. Para mayor desgracia, los empleos que les son disponibles, en el segmento más bajo del mercado, se encuentran a menudo en la franja del fin de semana, siendo incompatibles con los horarios del culto dominical $u$ otras actividades de carácter espiritual o confraternidad. Por todo ello, los pentecostales africanos hallan grandes dificultades para desempeñar una destacable acción social conjunta, interna o externa.

\section{CONCLUSIONES}

En este artículo se ha pasado revista a las diferencias que se esconden bajo el apelativo de "minorías religiosas" atendiendo, al tipo de modelo de pluralismo religioso vigente en un país y al tipo de "minoría" de que se hable, según criterios estadísticos, jurídicos y sociológicos. Estas diferencias resultan en desigualdades de facto que afectan la forma cómo se constituyen y cómo operan las congregaciones religiosas e, igualmente, el tipo de relaciones que mantienen con el entorno.

Para ejemplificar esta discusión en el contexto de un país de pluralismo moderado y muy reciente historia de inmigración como España, se ha escogido dos congregaciones cristianas de origen protestante implantadas en la ciudad de Málaga, una de las más internacionalizadas de Andalucía y el país entero. Ambas comparten el hecho de comunicarse en inglés y de estar formadas en prácticamente su totalidad por personas de un mismo origen pan-étnico, en este caso: uno anglosajón, el otro africano.

Se observan, sin embargo, diferencias importantes en las funciones y posición social de ambas congregaciones que repercuten en su situación desigualdad como minorías religiosas en España. Este punto se expresa detalladamente en el siguiente cuadro: 


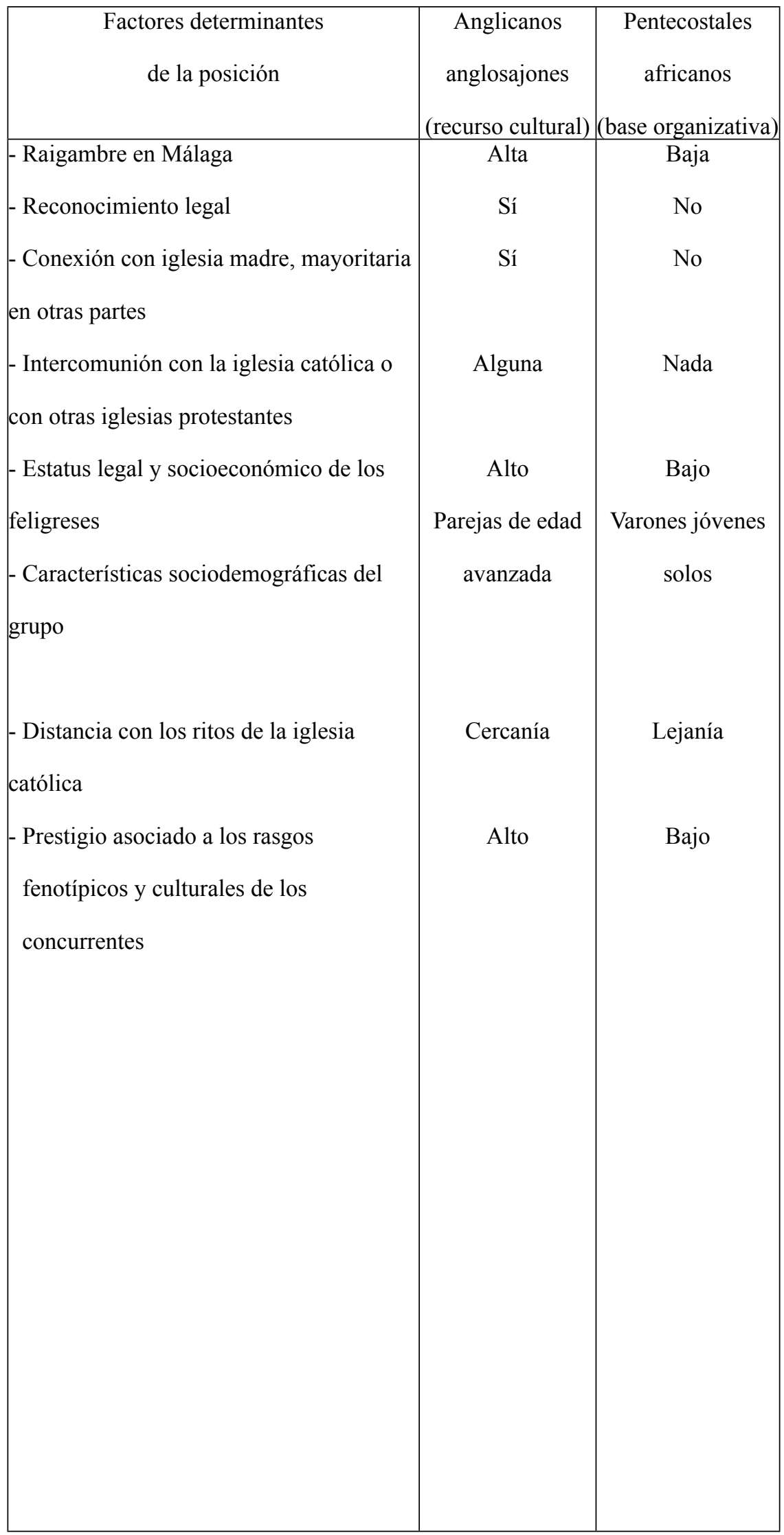




\begin{tabular}{|c|c|c|}
\hline Funciones de la congregación & $\begin{array}{c}\text { Anglicanos } \\
\text { anglosajones }\end{array}$ & $\begin{array}{c}\text { Pentecostales } \\
\text { africanos }\end{array}$ \\
\hline $\begin{array}{l}\text { - Vigilancia sobre la observancia de los } \\
\text { dogmas y modelos de comportamiento que } \\
\text { se predican }\end{array}$ & Baja & Alta \\
\hline $\begin{array}{l}\text { - Lugar de reivindicación de una identidad } \\
\text { cultural y religiosa }\end{array}$ & Más cultural & Más religiosa \\
\hline - Refugio ante las vicisitudes & Menos & Más \\
\hline $\begin{array}{l}\text { - Lugar de socialización de segundas y } \\
\text { sucesivas generaciones }\end{array}$ & No & Sí \\
\hline $\begin{array}{l}\text { - Lugar de encuentro para la planificación } \\
\text { de actividades lúdicas y sociales fuera de }\end{array}$ & Sí & No \\
\hline $\begin{array}{l}\text { la iglesia } \\
\text { - Acción social hacia el exterior }\end{array}$ & Moderada & Nula \\
\hline
\end{tabular}

El cuadro demuestra la relación existente entre la posición social de los grupos y las funciones que ejercen las congregaciones, y las funciones, a su vez, contribuyen a alimentar la imagen externa del grupo. Teniendo en cuenta que en términos weberianos, la posición social se obtiene de la suma de riqueza, poder y prestigio, africanos $\mathrm{y}$ anglosajones en España no se encuentran en igualdad de condiciones. La falta de estos atributos entre los africanos les lleva a replegarse sobre si mismos y a reforzar sus funciones internas. La congregación anglicana, por el contrario, goza de mejor aceptación por parte de la población autóctona, quizás por se ve como una mera trasplantación temporal de ritos religiosos no tan diferentes de los católicos.

Empero, a pesar de la percepción de que están ahí de paso, ni la iglesia anglicana de Málaga constituye por su larga historia un fenómeno temporal, ni las diferentes iglesias pentecostales africanas de Málaga tienen intención de detener sus actividades. Por el contrario, para los africanos inmigrados y probablemente sus hijos, la iglesia formará parte consustancial de su forma de incorporación al nuevo lugar de residencia. En términos de Cháves (1994) la congregación anglicana constituye un "recurso cultural" (en contexto de alta secularización individual y social) mientras que la congregación pentecostal resulta en una "base 
organizativa" (en contexto de alta secularización social pero baja secularización individual).

A pesar de las diferencias, ambas congregaciones permanecen invariablemente poco atractivas a otros grupos étnicos, locales o asentados, en consonancia con la discusión planteada al inicio de este artículo. Habida cuenta que, como señala Martin (2002:57), la religión en España ha pasado de ser casi-normativa a estar casi tan desalineada como en Francia, la mayoría de españoles se siente cómoda con el tipo de catolicismo que profesa, poco involucrado en su vida personal. Es un hecho, por ejemplo, que la Europa latina no responde al Pentecostalismo como la América Latina. La excepción la constituyen los gitanos, otra vez una minoría étnica secularmente marginada, que desde la década de los sesenta se organiza en torno a la Iglesia de Filadelfia, una iglesia de signo pentecostal adaptada a sus gustos y necesidades (Martin, 2002:48 y Cantón, 2004). Los otros españoles, a falta de búsqueda de liberación o emancipación, mantienen sus tradiciones e imaginario católico de forma residual y como parte de su identidad, mientras que asocian las demás corrientes a otros grupos étnicos y nacionales.

Por todo lo anterior, es bastante improbable que la mayoría de españoles nativos cambien su afiliación religiosa por otras iglesias nacionales. Ni el anglicanismo ni otras denominaciones evangélicas históricas atraen, porque recuerdan demasiado a la Iglesia Católica, todo y con su mayor liberalismo. Además, la asociación entre Iglesia y Estado es demasiado fuerte en Europa, a pesar de las fuerzas que desdibujan las fronteras. En todo caso y a medio plazo, la Iglesia Católica, si desea sobrevivir, puede verse abocada a una mayor apertura, como en la cuestión del ordenamiento de mujeres, a semejanza de lo ocurrido en el seno de la anglicana. En cambio, para que las iglesias pentecostales fueran más atractivas a los españoles nativos, habrían de superarse los prejuicios asociados a formas de religión alternativas y su vinculación con grupos étnicos minoritarios y de bajo prestigio. Desposeídas del estigma social y cultural, las nuevas iglesias podrían crecer libremente hasta estar en posición de concurrir con otros credos (Stark, 2006).

No obstante, como diversos autores señalan, es difícil imaginar un retroceso de la secularización en Europa, dado que cumple una función ideológica para muchos europeos, es la clave de la modernidad y del bienestar alcanzado (Casanova 2006). Un proceso de secularización que, al igual que se trasladó y caló del Norte al Sur del viejo continente, podría afectar a las nuevas poblaciones llegadas, hasta dejar sin contenido a sus propias iglesias implantadas. 
La iglesia anglicana, que ha permanecido por 150 años en Málaga, ha experimentado el mismo proceso de distanciamiento con su comunidad que el acontecido en la iglesia católica española. Esta iglesia subsiste por la aportación de un pequeño porcentaje de británicos que, sin embargo, no se establece de forma total y permanente en estas tierras, por lo que no se observan segundas ni terceras generaciones de feligreses. Por lo que conocemos de otros países, en cambio, el proceso no tiene porqué ser el de una paulatina secularización, sino que mientras en algunas iglesias pueden esperarse deserciones en la segunda generación (Crockett y Voas, 2006), otras se vuelven multiétnicas (Dhingra, 2004) o cambian su posición y relación con la sociedad en su conjunto.

Con todo, aunque los migrantes se exponen a la secularización al asentarse en territorio secularizado, debido a que la inmigración es un proceso continuo, los viejos migrantes pueden ser reemplazados por otros nuevos en las congregaciones. Como en el caso de Canadá (Beyer, 1997, citado en Esteban, 2007), se puede esperar una situación combinada: por un lado, un cierto grado de mantenimiento de las identidades religiosas tradicionales (católicas en nuestro caso) aunque poco fervientes; por otro, el incremento de identidades religiosas implantadas, asociadas a las minorías étnicas. Estas últimas tienen más posibilidades de expandirse entre las segundas generaciones en la medida en que estén menos socializadas por la Iglesia Oficial, habida cuenta que los hijos de los inmigrantes atienden en menor medida los colegios católicos del país (educación privada concertada en manos de la Iglesia). 


\section{REFERENCIAS BIBLIOGRÁFICAS}

Álvarez, Manuel (2002) Anticlericalismo y libertad de conciencia. Madrid: Centro de Estudios Políticos y Constitucionales.

Berger, Peter (1967) The sacred Canopy: elements of a sociological theory of religion. New York: Doubleday

Bethencourt, Francisco (1997) La Inquisición en la época moderna: España, Portugal e Italia, siglos XV a XIX. Madrid: Akal.

Beyer, Peter (1997) "Religious vitality in Canada: the complementarity of religious market and secularization perspectives". Journal for the Scientific Study of Religion, 36(2): 272-288.

Briones, Rafael; Carmen Castilla, Oscar Salguero, Celeste Jiménez, Sol Tarrés (2005)

"Incidencia sociocultural de la religión entre los inmigrantes en Andalucía”. Ponencia presentada al IV Seminario sobre la Investigación de la Inmigración Extranjera en Andalucía. Córdoba.

Bruce, Steve (1999) Choice and religion: a critique of rational choice theory. Oxford: Oxford University press.

Bruce, Steve (2002) God is dead: secularization in the West. Oxford: Blackwell.

Cantón, Manuela (2004) Gitanos pentecostales. Una mirada antropológica a la Iglesia Filadelfia en Andalucía. Sevilla: Signatura ediciones.

Chaves, Mark (1994) "Secularization as declining religious authority". Social Forces, 72(3): 749-774. 
Crockett, Alaisdair y David Voas (2006) "Generations of decline:

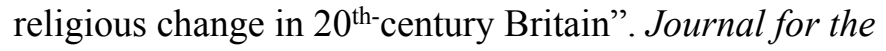
Scientific Study of Religion, 45(4): 567-584.

Davie, Grace (2000) "Religion in modern Britain: changing sociological assumptions”. Sociology, 34(1): 113-128.

De Arístegui, Gustavo (2005) La Yihad en España: la obsesión por reconquistar Al-Andalus. Madrid: La esfera de los libros.

Dhingra, Pawan (2004) "We're not a Korean American church any more: dilemas in constructing a multicultural church identity". Social Compass, 51(3): 367-379.

Esteban, Valeriano (2007) "La secularización en entredicho", comunicación presentada a las II Jornadas de Sociología: El Fenómeno Religioso. Sevilla. Fundación Centro de Estudios Andaluces. 13-14 junio.

Estruch, J., Gómez, J., Griera, M.M. y Iglesias, A. (2004) Les altres religions. Minories religioses a Catalunya, Barcelona: editorial Mediterrània.

Finke, Roger y Rodney Stark (2003) "The dynamics of religious economies" en M. Dillon (ed) Handbook of the Sociology of Religion. pp. 96-109. New York: Cambridge University press.

Grace-Hutchinson, M. (2001) The English cementery at Malaga, publicación de la Iglesia de Saint George en Málaga

Hamberg, Eva y Pettersson, Thorleif (1994) “The religious market: denominational competition and religious participation in contemporary Sweden". Journal for the Scientific Study of Religion, 33(2): 205-216.

King, Russel, Tony Warnes y Allan Williams (2000) Sunset lives: British retirement migration to the Mediterranean. Berg publishers. 
Lewis, Bernard (1995) Cultures in conflict: Christians, Muslims and Jews in the age of discovery. New York: Oxford University press.

Martin, David (2002) Pentecostalism: the world their parish. Oxford: Blackwell publishing.

Pérez-Agote, Alfonso y José A. Santiago (2005) La situación de la religión en España a principios del siglo XXI. Informe:

Opiniones y Actitudes $n^{\circ} 49$. Madrid: Centro de Investigaciones Sociológicas.

Pérez-Madrid, Francisca (2004) Inmigración y libertad religiosa. Un estudio desde la Ley de Extranjería. Madrid: Civitas ediciones.

Pérez-Yruela, Manuel y Sebastián Rinken (2005) La integración social de los inmigrantes en Andalucía. Córdoba: Consejo Superior de Investigaciones Científicas.

Piedrahita, Gabriel (2006) "Minorías étnico-religiosas en la Comunidad de Madrid: integración y conflictos". Estudios Geográficos, 261 (67): 579-606.

Pisati, Maurizio (2004) "One, none, and a hundred thousand: Italian's religious pluralism”. Polis, 18(2): 315-337.

Portes, Alejandro (1987) "What's an Ethnic Enclave? The Case for Conceptual Clarity". American Sociological Review, 52 (December) 6: 768-771.

Rodríguez, Vicente, M. Angeles Casado, Andreas Huber (2005) La migración de europeos retirados en España. Madrid: Consejo Superior de Investigaciones Científicas.

Rozenberg, Danielle (1996) "Minorías religiosas y construcción democrática en España. (Del monopolio de la Iglesia a la gestión del pluralismo)". Reis, 74: 245-265. 
Said, Edward (1979) Orientalism. New York: Vintage books.

Seglers, Alex (2005) La laicidad y sus matices. Granada: editorial Comares.

Stark, Rodney (2006) "An economics of religion" en R. Segal (ed) The Blackwell companion to the study of religion. Malden: Blackwell.

Torres de Castilla, Alfonso (1983) Historia de las persecuciones políticas y religiosas, ocurridas en Europa desde la Edad Media hasta nuestros días. Barcelona: Salvador Manero.

Yang, Fenggang y Helen R. Ebaugh (2001) "Religion and ethnicity among new immigrants: the impact of majority/minority status in home and host countries". Journal for the Scientific Study of Religion, 40(3): 367-378. 